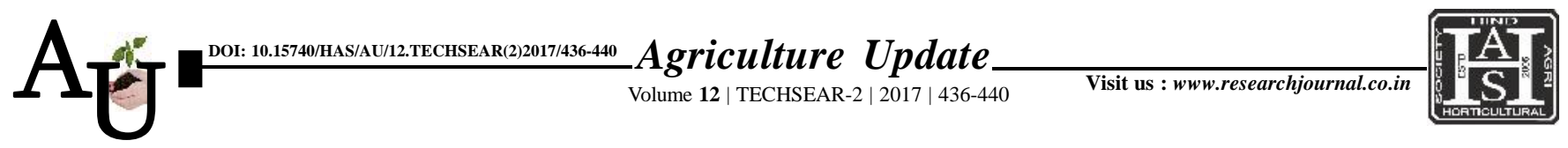

שe ISSN-0976-6847

\title{
Research Article: Bioefficacy of crude extracts from Simarouba glauca DC. against Plutella xylostella and Helicoverpa armigera
}

Article Chronicle : Received :

11.07.2017;

Accepted :

24.07.2017

KeY Words:

Simarouba glauca, Plutella xylostella, Helicoverpa armigera, Insecticidal activity, Antifeedant activity, Plant extracts

\section{S.S. BANGAR, M.S. DUDHARE, A.G. DESHMUKH AND H.A. WAGH}

SUMMARY : The present investigation was undertaken with the view of development of the new insecticidal biomolecule from Simarouba glauca DC. The crude methanolic refluxed extracts were screened (leaf, seed, root and bark) for insecticidal activity against Plutella xylostella and Helicoverpa armigera by leaf dip bioassay method. The extracts were found effective against Plutella xylostella showing highest 80 per cent mortality, whereas strong antifeedant activity was found against Helicoverpa armigera. The study revealed Simarouba glauca leaves and bark has very good potency against both insect pests assayed and can be exploited for management practices of agricultural pests. Further purification of extracts, characterization of active principal component and its conformation for bioactivity against wide range of agricultural pests will be helpful for identification of new source of biopesticide.

How to cite this article : Bangar, S.S., Dudhare, M.S., Deshmukh, A.G. and Wagh H.A. (2017).Bioefficacy of crude extracts from Simarouba glauca DC. against Plutella xylostella and Helicoverpa armigera. Agric. Update, 12(TECHSEAR-2) : 436-440; DOI: 10.15740/HAS/AU/12.TECHSEAR(2)2017/436-440.
Author for correspondence :

\section{S.S. BANGAR}

Vasantrao Naik College

of Agricultural

Biotechnology, (Dr.

P.D.K.V.) YAVATMAL

(M.S.) INDIA

Email:bangarsandesh

@ gmail.com

See end of the article for authors' affiliations 